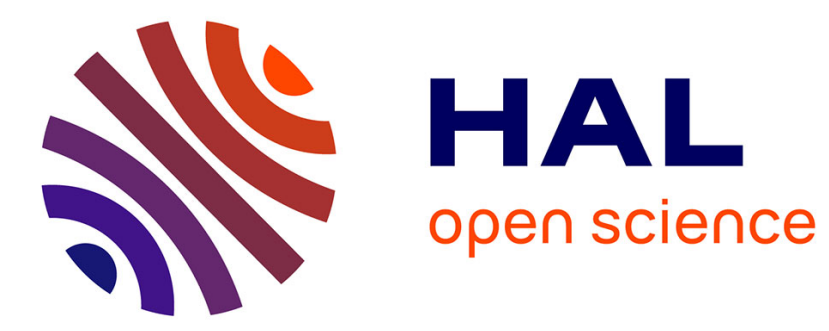

\title{
Managing Medicinal Risks in Self-Medication
}

Sylvie Fainzang

\section{To cite this version:}

Sylvie Fainzang. Managing Medicinal Risks in Self-Medication. Drug Safety, 2014, 37 (5), pp.333-342. 10.1007/s40264-014-0153-z . hal-02456625

\section{HAL Id: hal-02456625 \\ https://hal.science/hal-02456625}

Submitted on 24 Feb 2020

HAL is a multi-disciplinary open access archive for the deposit and dissemination of scientific research documents, whether they are published or not. The documents may come from teaching and research institutions in France or abroad, or from public or private research centers.
L'archive ouverte pluridisciplinaire HAL, est destinée au dépôt et à la diffusion de documents scientifiques de niveau recherche, publiés ou non, émanant des établissements d'enseignement et de recherche français ou étrangers, des laboratoires publics ou privés. 


\title{
Managing medicinal risks and treatment personalisation in the context of self-medication
}

\author{
Sylvie Fainzang
}

(Published in: Drug Safety, 37, 5, 2014, 333-342)

It is commonly thought that medicinal uses can be divided into "good uses" and "misuses", meaning, respectively, those conforming to medical recommendations, and those which fall into the category of inappropriate lay practices. In order to understand these practices, anthropology has shown the importance of not passing judgement in the light of medical knowledge, and of trying to decrypt their meaning, in particular by relating them to certain systems of thought or cultural representations. Lay medicinal uses follow their own logics, and are associated with how individuals perceive these medicines. In this respect, examining the uses of pharmaceuticals involves looking at perceptions of their efficacy and of their risks. If this question can be asked regarding patients holding a medical prescription - and this has indeed been the object of numerous social sciences studies ${ }^{[1,2,3,4]}$ - it can equally be asked about users who are not in possession of a prescription, in other words within the framework of self-medication - a context in which choices have to be made between the various medicinal solutions on offer. The framework of self-medication is in effect more open to medicinal misuse than the context of prescription management, at least if the problem is perceived from the point of view of biomedical science ${ }^{[5,6]}$. As a matter of fact, the risk associated with medicinal use is a central element in the growing debate on self-medication in the French public domain, and is often invoked by its critics. The practice is considered to be uncertain and risky, and worries health professionals, even though the public authorities largely promote self-medication today. Their worry relates to the patients' ability or inability to know when they must consult a doctor and how to manage their medicinal uses. In contrast to the biomedical or pharmacological view of self-medication, the anthropological approach seeks to understand the logics that underpin it. The question is thus raised of knowing how users choose the medicines they take and how they construct the modalities of their use. It would be an error to believe, however, that individuals are not concerned with safety and that they are not aware of the risks associated with drug consumption and self-medication. Indeed, users devise strategies aiming to reduce these risks.

Yet, as we will see, though these practices sometimes escape biological logic, the mechanisms on which they are based do not necessarily break away from medical recommendations. Based on a study carried out on the conditions and motivations for selfmedication in France, I will examine the strategies adopted to reduce any associated risks. I will show that while the modalities of medicinal use result from symbolic logics tnifhe questiaktodabject, they are nevertheless inspired by principles borrowed from biomedical logic.

The studies relating to lay medicinal use all highlight the resistance individuals express to these substances ${ }^{[7,8,4]}$, or even their aversion to them ${ }^{[9,10]}$. These forms of resistance have resulted in some interesting typologies, that aim to account for the refusals and rearrangements 
that take place in terms of these medicines. In the direction taken by Dowel and Hudson ${ }^{[11]}$ who distinguished between "passive users", "active users" and "rejecters", Pound et al. ${ }^{[12]}$ distinguish between "passive accepters", "active accepters", "modifiers" and "rejecters". Chamberlain et al. [7] however remarked that these typologies do not take into account the functioning of the complex phenomenon of resistance, to the extent that attitudes differ according to the medicines (some people resist certain medicines and not others) and according to the context (indeed, some people can refuse one medicine in situation $\mathrm{X}$ but not in situation $\mathrm{Y}$ ). They noted that resistance is complex and variable, as Britten et al. ${ }^{[10]}$ and Van der Geest ${ }^{[13]}$ also highlighted.

Such resistance to pharmacology has led Webster et al. ${ }^{[14]}$ to believe that users act according to a logic of "lay pharmacology", since individuals carefully examine the medicines' actions, therapeutic properties and effects. However, it seems that we can go as far as considering that they realise a form of "lay pharmacovigilance", to the extent that these rearrangements are not only based on a desire to maximise the effects but also to minimise the risks ${ }^{[15]}$. In these conditions, beyond the diverse causes of resistance brought to light in these studies, it is appropriate to examine the strategies that organise it and to unearth the symbolic logics of lay practices intended to manage the risks associated with consuming pharmaceuticals within the framework of self-medication.

This article rests on empirical research concerning the social, cultural and cognitive mechanisms underpinning individual practices as regards self-medication ${ }^{[16]}$. To understand these mechanisms, anthropologists feel the need to question the categories usually used on this subject. Indeed, to learn that an individual resorts to self-medication only in benign situations, does not sufficiently illuminate what $\mathrm{s} / \mathrm{he}$ regards as a "benign situation", what $\mathrm{s} / \mathrm{he}$ calls "resorting to self-medication", her/his reasons for choosing such a drug or her/his strategies to reduce the associated risks or to increase its effectiveness. Such a decoding requires a critical approach of the very notions on which the public health discourse is based by testing their relevance through fieldwork. This involves studying a phenomenon without prejudging what the users do and think; thus, the practices and categories must be considered without any preconceptions. If the public health objective is to limit the risks involved in self-medication and to define the conditions of this recourse, the objective of anthropology is, not to attend to people's medical safety or to a safe use of drugs (a normative position that anthropologists should not assume), but to understand the social practices at work, the way in which individuals manage the risk associated with self-medication, and the meaning their practices take. This means that, even if the answers to these questions may ultimately contribute to improving public health, this must not be the prime and sole aim. Otherwise, we run the risk of formulating questions that prevent us from grasping some facets of social life. It is precisely these unexpected aspects of social life that can be highlighted by anthropology.

\section{Research setting and method}

The research was carried out in Paris and involved around 40 people from diverse social environments. The people participating in the research were for the most part met through the "snowball" method. The first informants, who were in keeping with the population chosen for 
the research, introduced us to other potential informants through their networks of acquaintances, who in turn referred us to other people who were added to the sample group, which was built in this way. This allowed us to approach a relatively diverse population, thanks to the diversity of the acquaintance networks used: some suggested members of their family, others work colleagues, and others again referred us to association members, friends or neighbours who by the end proved to be very different from the first informants (in their social, economic and ideological positions). By forming a group of informants using close personal contacts, we move away from the first types of people studied. Moreover, we chose to multiply the points of departure of the networks, favourising the constitution of what could be considered a plurality of "snowballs", each original snowflake coming along a different path. Indeed, this procedure reduced the difficulty of approaching people to discuss a topic as personal and intimate as treating one's body and affliction, without having to pass through the intermediary of health professionals.

It was not always possible here to observe, on the spot, people's actual actions and gestures. The research was carried out at people's homes, and thus consisted for a large part of interviews - even if, in some cases, the interviews were combined with in situ observation - concerning the choices people made when faced with a symptom. The research allowed me to collect a certain number of accounts of pathological episodes, in order to understand the different scenarios of self-medicinal use. The interviews concerned established facts. A technique frequently used in quantitative research on self-medication is to question informants as to how they intend to behave when faced with a hypothetical pathological or symptomatic situation. But this is an abstract situation, from which reality cannot be inferred. In this regard, an interview that only aims to ask questions such as: "What medicines do you take when you are ill?" as is often envisaged by questionnaire-based inquiries, does not provide much more information than if the subject is asked: "What medicine would you take if you were ill?" Interviews should resituate the practice of self-medication in its context and refer to lived events (past or present). In contrast to a study that deals with the "intended", it seemed preferable to study practice that has been carried out, when it is not possible to actually observe it. The past provides more information than the conditional.

Moreover, I collected information on the conditions in which drugs detained in the household pharmacies of the people studied were acquired and used in order to obtain complementary material and to verify their statements, which sometimes aimed to conform to what they judged to be socially appropriate. To avoid this pitfall as best I could, I avoided contacting the informants through the intermediary of a doctor, which could have risked associating my work with that of a health professional, and could have induced the subjects to produce discourses showing them to be "good patients".

Although the public authorities largely promote self-medication today (through a decree authorising direct access to medicines and delisting of a certain number of pharmaceutical products), the issue of safety in self-medication is a central concern; its practice is considered to be uncertain and risky, and worries health professionals. The principal risk they mention is that of inadvisable drug use (overdoses, drug interactions, etc.). To suppress this uncertainty and to 
limit these risks, public authorities together with medical authorities have produced several recommendations for users aiming to structure the practice and define the conditions of use. It is recommended that this recourse is limited to benign situations, that the remains of previous prescriptions should not to be used and that the advice of a pharmacist should to be sought. These practices can be summarized by the notion of "responsible self-medication". These recommendations are notably diffused through the "ten commandments for self-medication" circulated on several sites destined for the general public. Notable among these recommendations are the assertions that one must take note of patient information leaflets to be aware of any adverse side-effects ("Read the accompanying leaflet of a medicine carefully. It will tell you its indications, recommended dosages according to age, weight and potential adverse side-effects..."), and that one should not take medicines prescribed for somebody else ("A treatment that suits you may not suit someone else", "A medicine that worked very well for a member of your family could have no effect, or even be dangerous, for you") and that one should ask advice from a pharmacist ("To provide the best advice, the pharmacist must know who the medicine is for"). So how do users respond to these recommendations?

In order to make their decisions, users refer simultaneously to various sources of information previous prescriptions, advice from friends and family, advertisements, Internet searches - and to their own experience. In this regard, although self-medication implies personal choice, individuals are never totally independent - they are subject to a thousand influences ${ }^{[17]}$, from those around them as well as the whole society. Subjects are therefore never alone in dealing with their symptom and their medicinal options. They are surrounded by information coming to them from sources as varied as health campaigns, previous medical consultations, pharmacists, friends and family, pharmaceutical leaflets and the media, notably the press, the television and the Internet.

Clearly, the information found on the Internet does not only come from professional sites. Information distributed by specialists on sites for the general public, whether approved by health institutions or not, is collected together with information based on the experience of other web users, as told on discussion forums ${ }^{[18,19]}$. The two are sometimes mixed in accounts given by patients. They search the Internet for several different objectives. While the aim may be to obtain information about an affliction, its causes and possible progression, it is also done in order to inquire about existing medicinal choices, precautions to be taken and conditions to be respected in order to assure the safety of the medicine, and to find out about any risks associated with its use. One user thus explained her problem on a forum and asked: "Is it possible to take Doliprane at the same time as Zelitrex? I have herpes on my lip which is very painful and a splitting migraine. I am desperate, please reply." Information gathered from the experience of other Internet users is thus added to advice from people close to the user (family, friends and colleagues). The aim is to benefit from the experience of others, despite their anonymity, concerning the effects of a medicine, the level of satisfaction or, inversely, on their potential side effects. Searching for opinions on forums can sometimes replace asking a pharmacist, either because it is embarrassing (a pharmacy does not lend itself to intimate talk about the body) or because it is more convenient (the advice arrives quicker), or simply to gain several points of view. 


\section{Quantitative logics/qualitative logics}

Individuals' choices concerning medicines are constructed through various logics, some quantitative, others qualitative.

For example, concern over the consumption of too many pharmaceuticals leads some people, using quantitative reasoning, to decide to reduce the number of days they take a medicine for. However, these strategies can, in turn, generate risk, similarly to strategies that involve modifying the instructions (indications, dosages, precautions of use) that accompany medicinal prescriptions. This is the case for antibiotics, for which the high consumption levels in France, generally attributed to patient appetite for this type of medicine, presents serious problems for public health considering the drug resistance caused by this overconsumption, and the poor prospects of being able to find molecules that could replace today's antibiotics in the near future. This problem drove the Caisse nationale d'assurance maladie (The National Health Insurance Fund) to produce an information video-clip destined for the general public, entitled "Antibiotics are not Automatic", in which the explicit message is that one should not consume too many antibiotics. Thus, in response to this message, some patients, strongly convinced that excessive consumption of antibiotics carries risks, claim to be perfectly aware of this risk and ensure, when they do consume them, they stop the treatment as soon as the symptoms disappear, which often means after two days. It is precisely in accordance with the concern to not consume too many antibiotics that some users think it reasonable to reduce the time these drugs are taken for (whether they are prescribed or self-medicated), a strategy that responds to the advice diffused by the health authorities to not abuse this type of medicine. And so this practice results in an increase in drug resistant germs, even when the intention of the users is to reduce the phenomenon.

Likewise, managing the quantity of pharmaceutical products taken is seen as a means of reducing the iatrogenic effects of medicines. Thus, fear of medicinal interactions sometimes leads subjects to choose to limit the number of medicines they consume. Mrs $\mathrm{N}$ fears that accumulating and mixing several chemical products could induce harmful effects so she limits her medicinal consumption to three brands in order to reduce this risk. She believes that the iatrogenic risks are associated with the quantity rather than the quality of different pharmaceutical products.

Other mechanisms govern the choice of type or quality of medicines to be consumed. For instance, the pharmaceutical consumption may be refused when the risk is perceived to reside in the nature of the medicine, in the molecule it is composed of and in the danger inherent in its uncontrolled ingestion - that is to say, in the qualitative aspect of the medicine. This is what leads subjects to avoid, sometimes definitively, a certain class of products (such as anti-inflammatories for example). Other users systematically avoid taking two medicines at the same time when one is of a determined pharmaceutical class (anti-inflammatories, antibiotics). The perception of risk does not only depend on the perception a subject has of a medicine but also on what a medicine is. For example, some subjects claim to be against the consumption of psychotropic drugs but nevertheless choose to take a tranquiliser to treat sleeping problems (either difficulties in getting to sleep or waking during the night). This is partly explained by the status given to products such 
as hypnotic drugs, which are often simply considered to be "calming" and not to have a chemical action on the psyche. ${ }^{1}$ Moreover, some users do not consider a medicine to be risky if it is not a synthetic product. This goes for herbal medicines with which subjects freely practice selfmedication without caution despite the potentially noxious effects of their use - just like other medicines -, little aware of the fact that a medicine carries risk as soon as it has an action. Or indeed, some medicines are not considered risky if their consumption is not intended to solve a health problem. This is the case for medicines taken "to lose weight" which several patients take for aesthetic and non-medical reasons. Thus Mrs M does not distinguish between nutritional supplements based on green tea and weight-loss drugs which she considers to be cosmetic rather than therapeutic. The definition of a medicine here depends on the purpose for which it is consumed.

In parallel to risk management strategies, users develop strategies to maximise the efficacy of medicines. Thus, in the same way that the doses prescribed by a doctor may be increased in order to heighten the effects ${ }^{[21,22]}$, certain medicines chosen for self-medication may also be taken at a higher dose than recommended in the leaflet or in a previous prescription, a practice resulting from quantitative logic. In some regards, the management of medicines consumed in the context of self-medication follows logics comparable to those that organise behaviour regarding prescribed medicines. In terms of how patients comply with their prescriptions, I have provided evidence of the various logics that underpin the modification of prescriptions. I have identified a cumulation logic, consisting of increasing dosages or even accumulating several medicines in order to increase the chances of recovery and an identity logic, consisting of modifying a treatment based on identifying a link between oneself and the product, whether one is (or considers oneself to be) fat or thin, strong or weak, adult or child, man or woman, resistant or frail, etc. ${ }^{[15]}$. I have shown that such reasoning partly informs the choice as to whether to adhere to or modify the doses prescribed. These various logics also bear on how the medicines consumed within the framework of self-medication are managed. Thus we find both cumulative logic and identity logic within the practice of self-medication, both in the search for better efficacy and in order to reduce the negative effects of medicines. Recommended doses, either from a previous consultation resulting in a prescription, in the patient information leaflet of a medicine or given by a pharmacist, can thus sometimes be increased in order to boost efficacy, or in contrast, reduced to avoid inducing iatrogenic effects.

\section{Risk in itself/risk for oneself}

Exclusive or combined recourse to quantitative or qualitative logics may be done in order to manage the risk associated with medicines. The strategies adopted by subjects differ depending on whether they consider the risk to be inherent in the substance or linked to its modes of use. In the first case, subjects tend to eliminate the product in question from the arsenal of drugs they could potentially consume, in the second case, they try to neutralise the risks by modifying recommended doses or modes of consumption, whether the dosage is indicated in the patient

\footnotetext{
${ }^{1}$ On the perception of "calming" medicine, see Haxaire ${ }^{[20]}$.
} 
information leaflet or figures in a previous prescription for the same medicine. The strategies thus follow mechanisms which differ both according to the individuals and to the medicines they depend on whether the risk is perceived to be linked to the nature of the medicine in itself (the type of pharmaceutical product, their adverse side effects on certain functions or certain organs), or to its incompatibility with the subject (in relation to their personal characteristics, or their ability to absorb the medicine, their sensitivity, susceptibility or responsiveness, etc.). A desire to limit medicinal risks then leads subjects to closely observe their effects in order to attempt to adapt the doses to their bodies, in connection with the recognition of a relationship between the medicine and the individual, in its singularity: "I will need more than that! I am pretty tough," or "I will only take a tiny bit, less than they say in the leaflet, because I am very responsive to medicines." The importance placed on this relationship leads individuals to choose to modify how the medicine is taken or the dosage when they deem the recommendations to be incompatible to their specific case.

Risk management associated with the practice of self-medication thus follows various logics organised around the duality between the risk of the medicine in itself and the risk of the medicine for oneself. This point is illustrated with two examples: Mr P, a 42-year-old industrial designer, not eager to practice self-medication, nevertheless decides to take an antiemetic with confidence because he has once given it to his dog, and that this experience, to which he now assigns the value of a test, led him to be sure of the absence of harmful effects. Mrs J, a speech therapist, on the other hand, gets her medicines "tested" by a radiesthesist to verify their safety and efficacy. She is driven by a suspicion of the medicine and a fear that taking it would be wrong (whether the product was recommended by a pharmacist or chosen by herself) to resort to divination in order to verify the suitability of the treatment in her case. "He moves his antenna over the medicines to see if they react in order to test which ones respond, to check if they are safe and if they will work for me," she explained, her objective being to ensure that the medicine was well adapted to her particular case. It is in connection with the risk in itself that Mr P made sure his dog responded well to the anti-emetic before he took it. On the other hand, it is in connection with the risk of the medicine for oneself that Mrs J. relies on a radiesthesist to make sure a medicine suits her and is appropriate to herself and her body.

\section{Undesirable effects and desired effects}

The existence of adverse side effects is not necessarily an obstacle to self-medication in itself (neither is it necessarily an obstacle to compliance). While it is true that reading about the sideeffects in pharmaceutical leaflets sometimes dissuades patients from taking the medicines prescribed, the opposite can also apply where the subject interprets their presence as a sign of genuine efficacy to the point that however "adverse" this effect can be, the subject still does not envisage ending the treatment: the effects, good or bad, are a sign of the efficacy of the medicine and prove that one should keep taking it, without the subject considering the possibility of unfortunate consequences. For Mr B, "a good medicine is one that does something".

The significance here is in the type of effect more than its "adverse" or "secondary" character of which the distinction is far from clear for the users, considering the ambiguity of these notions 
in the pharmaceutical leaflets. While, strictly speaking, a "secondary side effect" is a non-desired consequence, induced by the administration of a drug, and which is additional to the primary desired effect during the application of a treatment for a given indication, an "adverse side effect" is "a response to a drug that is noxious and unintended and occurs at doses normally used in man for the prophylaxis, diagnosis or therapy of disease, or for the recovery, correction or modification of physiological function". ${ }^{2}$ In this regard, in France, mentioning "side effects" on a pharmaceutical leaflet carries less negative connotations than saying "adverse side effects". It is in fact in this sense that the WHO intends these two notions to be used.

Yet it is noticeable that some medicines are chosen precisely for their side effects, and not for the intended indication of the medicine, transforming the side effect into the desired, and so primary, effect. In this case, the side effect is no longer simply a sign of efficacy, but the vector of a new efficacy, that leads to a drug use that is not in accordance with the indications but with the side effects or, we could say, because of the side effects. The side effect can thus be identified as a "side benefit". Indeed, some medicines are chosen precisely for their adverse sideeffects. For example, certain antihistamines (such as Polaramine), or cough medicines (such as Toplexil) are sometimes taken as hypnotics because of the drowsiness they induce. In this way Mrs L uses Neo-codion to curb the difficulties her child experiences in getting to sleep - she thinks he is too excited in the evening. Even though drowsiness is a "possible adverse side effect" of the medicine, induced by the presence of codeine, it is used precisely for this effect, and not for its indication as a cough mixture. Here the subjects choose the medicine because of its sedative qualities, their decision supported by the recommendation in the patient information leaflet to take the substance in the evening. This is the case for Lexomil which users often take not for the indicated use (which is a symptomatic treatment of manifestations of severe and/or incapacitating anxiety), but in order to induce drowsiness, considered to be one of the adverse side effects of this medicine. ${ }^{3}$ Such forms of use show that a side effect normally deemed undesirable can in fact become a desired effect.

\section{Users and biomedical logics}

Just as users adjust the posology indicated in the leaflet partly in response to the concern to not over-consume medicines that could potentially harm their health, they also resort to such practices with the intention of arriving at an optimal use of the medicines, based on a realignment between cumulative logic and identity logic, and between efficacy and safety. The definitions or redefinitions of treatments in self-medication are based on a logic the subjects perceive to be medical, to the extent that they are convinced that in this way they are conforming to the safety precautions, and are adapting their self-prescription to their bodies and their unique characteristics (their age, sex, weight, etc.).

\footnotetext{
${ }^{2}$ According to the WHO and EU official definition.

${ }^{3}$ We should note that the confusion between side effects and adverse side effects is maintained in the way the pharmaceutical information leaflets are written, where neuro-vegetative effects such as drowsiness, induced by certain molecules, are sometimes mentioned in the side effects and sometimes in the adverse side effects.
} 
Certainly, some of the strategies devised by subjects to reduce the risk or maximise the efficacy of a treatment sometimes totally escape scientific logic. For example, using one's dog's experience or a radiesthesist's pendulum are techniques of validation which do not pertain to the biomedical field. However, my intention here is not to discriminate between "good" and "bad" practices when managing risks, but to understand the symbolic logic to which this risk management relates and the mechanisms according to which it is elaborated. Yet, when $\mathrm{Mr} \mathrm{P}$ decides to take an anti-emetic drug only after he has made sure that his dog has tolerated it well, the aim is to be sure of the harmlessness and effectiveness of a drug from the experience of someone of his close circle (to which the dog belongs). His decision results from an approach which, in his eyes, makes his practice a validated, proven technique, opposing experience-based medicine with evidence-based medicine.

Likewise, when Mr J has her medicines "tested" by a radiesthesist to verify their safety and efficacy, she does this believing she is complying with medical recommendations and ensuring the medicine is suitable for her; she is perfectly aware of the need for a treatment to be adapted to each individual, and resorts to dowsing to test the drugs that are advised to her, in order to make sure that they are appropriate to her case. Thus, her strategy borrows from a medical discourse stressing that treatments must be adapted to individuals organisms and characteristics. This is an example of a strategy which is not only anchored in syncretic cultural logic but borrows from, while radically distorting, medical logic. The need for a treatment to be adapted to a person is in fact what the majority of health professionals underline, explaining (among the reasons justifying the need to ask for advice from a pharmacist), that each person reacts differently to drugs. By her behaviour, this lady seeks to conform to instructions diffused by the medical discourse, namely that the treatment should be personalised.

Therefore, although subjects may behave contrary to the recommendations of health professionals, they borrow their logics from medical discourse. After a lecture in which he explained the Filipino concept of hiang (which refers to the belief that a medicine should fit the person that takes it), Van der Geest ${ }^{[23]}$ writes that a pharmacologist perceptively remarked that this "personal fitting/not fitting was what clinical pharmacologists were struggling with and trying to apply in new ways of testing". However, as we have seen here, the principle of personalising treatment exists well beyond such tests since it structures the medicinal practices of western patients with strategies that can prove to be totally foreign to medical logic.

\section{Conclusion}

The strategies employed within the practice of self-medication aim to both minimise the risks associated with medicines and to maximise their effect. There is thus a tension between two objectives: the search for efficacy and the prevention or management of risk. Safety and efficacy are considered simultaneously. Subjects seek to achieve a balance between the two, that is to say they search for efficacy with minimal risk by applying a balancing principle. This balancing between a given substance and one's body, which is considered according to an individual's personal rationality, is underpinned by symbolic, cultural or idiosyncratic logic. 
The logics underpinning self-medication (to manage risk and obtain efficacy) are partly comparable to those underpinning prescription compliance (or non-compliance). However, the balance here leans towards a different recombination, in that these logics integrate more decisively the need for the subjects to establish an appropriate relationship, in accordance with personal rationalities, between a given substance and their bodies. The decision to modify the posology of a treatment or to verify the suitability of a medicine to one's personal bodily characteristics, by using what I have called cumulative logic and identity logic, or by means of the validation techniques mentioned above, is founded on the internalisation of learned behavioural norms, transmitted during the whole process of patient socialisation by health professionals.

However, these practices are not perceived to conflict with medical recommendations and although they do not echo professional logics, they borrow from biomedical ones. Subjects perceive them to be wholly in keeping with advice to be prudent, to be aware of the risks associated with medicines and to choose personalised treatments. Indeed, it is in order to reduce the risks of medicines that subjects adapt and personalise their treatments. As we have seen, the necessity for treatments to be adapted to an individual is highlighted by the majority of health professionals themselves; they point out in their recommendations to users that each person reacts differently to medicines. The methods of validation used by some subjects thus aim to respond to the instructions diffused by medical thinking, namely that treatments should be personalised. While their choices may be structured according to symbolic and cultural logics, subjects feed off medical notions to formulate their practices, taking recourse to strategies of validation, verification, experimentation or personalisation.

\section{References}

1. Britten N., 2008, Medicines and Society. Patients, Professionals and the Dominance of Pharmaceuticals, Houndmills: Palgrave Macmillan.

2. Fainzang S., 2001, Médicaments et sociétés. Le patient, le médecin et l'ordonnance, Paris, Presses Universitaires de France.

3. Sarradon-Eck A., 2007, Le sens de l'observance. Ethnographie des pratiques médicamenteuses de personnes hypertendues, Sciences sociales et santé, 25, 2, 5-36.

4. Van der Geest S. and S. R. Whyte, 2003, Popularité et scepticisme. Opinions contrastées sur les médicaments, Anthropologie et sociétés, 27, 2: 97-117.

5. Hughes C.M., J.C. McElnay, G.F. Fleming, 2001, Benefits and risks of self-medication, Drug Safety, 24, 14, 1027-37.

6. Ruiz M.E., 2010, Risks of Self-medication practices, Current Drug Safety, 5, 315-323.

7. Chamberlain K., H. Maden, J. Gabe, K. Dew, P. Norris, 2011, Forms of resistance to medications within New Zealand households, Medische Antropologie, 23, 2, 299-307.

8. Fainzang S., 2005, Religious Attitudes toward Prescriptions, Medicines and Doctors in France, Culture, Medicine and Psychiatry, 29, 4: 457-476. 
9. Britten N., F. Stevenson, J. Gafaranga, C. Barry, C. Bradley, 2004, The expression of aversion to medicines in general practice consultations, Soc SC \& med, 59, 1495-1503.

10. Britten N., R. Riley, M. Morgan, 2010, Resisting Psychotropic Medicines: a synthesis of qualitative studies of medicines use, Advances in psychiatric treatment, 16, 207-18.

11. Dowel J. and H. Hudson, 1997, A qualitative study of medication-taking behaviour in primary care, Family Practices, 14, 369-375.

12. Pound P., N. Britten, M. Morgan, L. Yardley, C. Pope, G. Daker-White, R. Campbell, 2005, Resisting Medicines: a Synthesis of Qualitative Studies of Medicine Taking, Soc Sc and med 61: 133-55.

13. Van der Geest S., 2010, Why are pharmaceuticals sometimes liked and sometimes disliked, Viennese Ethnomedicine Newsletter, 12, 2-3, 15-20.

14. Webster A, C. Douglas and G. Lewis, 2009, Making sense of Medicines: Lay pharmacology and Narratives of safety and efficacy. Science as culture, 18, 2: 233-47.

15. Fainzang S., 2010, Discourse on safe drug use, symbolic logics and ethical aspects, Drug safety, 33, 8: 1-7.

16. Fainzang S., 2012, L'automédication ou les mirages de l'autonomie, Paris, Presses Universitaires de France.

17. Massé R., 2003, Ethique et santé publique. Enjeux, valeurs, normativités. Québec, Presses de l'Université Laval.

18. Hardey M., 1999, Doctor in the house: the Internet as a source of lay health knowledge and the challenge to expertise, Sociology of Health and Illness, 21, 6, 820-835.

19. Akrich M. \& Méadel C., 2002, Prendre ses médicaments / prendre la parole : les usages des médicaments par les patients dans les listes de discussion électroniques, Sciences Sociales et Santé, 20, 1 (special issue : Les médicaments : des prescriptions aux usages), 89-116.

20. Haxaire C., 2001, Calmer les nerfs: automédication, observance et dépendance à l'égard des médicaments psychotropes, Sciences sociales et santé (special issue : Les médicaments: des prescriptions aux usages), 20, 1, 63-86.

21. Van der Geest S. \& Whyte S.R., 1988, The Context of Medicines in Developing Countries, Dordrecht: Kluwer Academic Publishers.

22. Etkin N. L., 1992, Side Effects: Cultural constructions and reinterpretations of western pharmaceuticals, Medical Anthropology Quarterly 6: 99-113.

23. Van der Geest S., 2012, Discussing and testing efficacy, RIM, 4, 1, 1-13. 